shadows which suggested old calcified tuberculous gland at the root of the lung, but there was no evidence of any changes in the suprarenal glands. A Mantoux test gave a marked positive reaction with vesiculation, followed by induration, which persisted for several weeks in dilution 1 in 10,000 ; with dilutions 1 in 100,000 and 1 in $1,000,000$ the results were negative. There was a marked general reaction, the temperature rose to $103.8^{\circ} \mathrm{F}$. and the pulse to 112 per minute, with headache, recovery being only completed on the fifth day. There were no symptoms pointing to a focal reaction. Laboratory investigations showed: red cells per c.mm., 6,010,000 ; haemoglobin, 94 per cent. ; colour index 0.78 ; white cells per c.mm., 6,800. Differential count gave: polymorphonuclears, 43.2 per cent.; lymphocytes, 51.2 per cent. ; and eosinophils, 5.6 per cent. Meinicke reaction negative. Blocd urea $40 \mathrm{mg}$. per cent. Urine normal. Blood sugar fasting, and twenty-four hours after an injection of eucortone, $72 \mathrm{mg}$. per cent. ; after 50 grams dextrose halfhourly readings gave the figures $109,83,72$, and 80 . On another occasion, ninety-six hours after the last injection of eucortone, the blood sugar was $80 \mathrm{mg}$. per cent. ; the boy felt weak and fainted. The blood pressure was 78/50. After the administration of eucortone, $5 \mathrm{c} . \mathrm{cm}$. intravenously, and 50 grams of dextrose by mouth half-hourly estimations of blood sugar yielded the following results, 117, 113, 94,68 , and 78 . Blood pressure readings taken at ten-minute intervals after an injection of eucortone showed no rise of blood pressure.

\section{Progress of Case}

From February 6th till March 15th, inclusive, the patient received $5 \mathrm{c} . \mathrm{cm}$. eucortone intravenously each day, with the exception of the ninety-six hours above-mentioned. Under this treatment he remained free of most of his symptoms, such as vomiting, insomnia, anorexia; but there was only a 'gain of $2 \mathrm{lb}$. in weight. There was but slight lessening of pigmentation, and the blood pressure varied between 70/50 and 78/50. On March 1st three horizontal lineae atrophicae had appeared on either side of the spine opposite the eighth and ninth dorsal spinous processes. Lines of lighter colour, like those already mentioned above, had appeared, two on each side, symmetrically placed along the pectoral margin of the axilla, and one running from the sternal notch towards the umbilicus.

On March 16th whole-gland suprarenal (Armour) was substituted for the eucortone; three tablets, each of 2 grains dried gland ( $=10$ grains fresh gland), were given by mouth thrice daily. Within two days the patient expressed himself as feeling much better and stronger than he had done for many weeks. In the following ten days he gained $3 \mathrm{lb}$. in weight and the blood pressure rose to $90 / 55$.

On March 31st whole-gland suprarenal was replaced by a special extract of cortex prepared by Allen and Hanburys for oral administration. It was given in doses as suggested, but the gland equivalent was unknown to me at the time. Within twenty-four hours the lad said he did not feel so well, his appetite began to fail, there was immediate loss of weight, and the blood pressure fell to $78 / 48$. It was then found that this liquid extract, which was being given in doses of half an ounce thrice daily by mouth, only contained 1 gram of cortex per $3 \mathrm{c} . \mathrm{cm}$. It also contained 0.05 per cent. adrenaline. A return to whole gland by mouth was made on April 5th, with immediate benefit; all previous symptoms disappeared, the blood pressure rose to $88 / 58$ in forty-eight hours, weight increased, and appetite was excellent. During the ensuing two weeks improvement was rapid; he was able to walk several miles, muscular power was good ; to exercises directed to correct the kyphosis he responded well. The pigmentation was diminishing very considerably, and the blood pressure remained higher than previously. The pulse sounds noted during sphygmomanometrical readings appeared almost normal. About the middle of April it was noticed that the breasts were enlarged, resembling those of a girl a year before puberty, but without changes in the nipples. During fortyeight hours, April 18th to 20th, treatment was discontinued, with no obvious ill effect.

On April 21st cortin organon, $5 \mathrm{c.cm}$. by mouth, was given. By the evening of that day symptoms of suprarenal insufficiency developed. These had not been noticed during the previous two days, when treatment had been withheld. After three days on $5 \mathrm{c} . \mathrm{cm}$. by mouth, $5 \mathrm{c} . \mathrm{cm}$. were given twice daily intramuscularly, with some improvement. Cortin is a preparation of suprarenal cortex made at Oss in Holland by N. V. Organon, who very kindly sent me a supply for a trial at the instance of Dr. Alison Macbeth: $1 \mathrm{c} . \mathrm{cm}$. represents 50 grams of fresh gland. The dose advised-namely, 5 c.cm., intravenously-for maintenance is doubtless about correct, and corresponds fairly closely to that of eucortone.

A second return was made to dried whole gland, and the patient took his discharge from hospital on May 4th, 1933, with a supply of tablets. He came up once two weeks later for more tablets, and then disappeared; all efforts to trace him failed. On July 1st, 1933, he returned in a condition of collapse, with all his previous symptoms returned. Weight, $119 \mathrm{lb}$; ; temperature, $98^{\circ}$ to $99^{\circ} \mathrm{F}$.; pulse $72 / 84$; blood pressure, 60/36. There were present extreme asthenia, negativism, nausea, vomiting, and abdominal pain. During the first week, 10 c.cm. eucortone was given daily; later an oral preparation of eucortone, made by Allen and Hanburys, was tried, and the addition of adrenaline subcutaneously was made. The patient continued to lose weight, and it was impossible to get him to take nourishment. A return was made to intravenous eucortone, kindly provided by Al'en and Hanburys: $10 \mathrm{c} . \mathrm{cm}$. were given twice on the first day (July 22nd) and the second day, then 10 and $5 \mathrm{c} . \mathrm{cm}$., and thereafter 5 and $5 \mathrm{c} . \mathrm{cm}$. each day. There was some response in that a little nourishment was taken and the extreme sense of weakness was less marked; the blood pressure remained at $60 / 36$. Eucortone was then discontinued, as the supply had come to an end. Twenty-four hours later the patient collapsed, became comatose, and died. Necropsy was refused.

\section{REFERENCES}

${ }^{1}$ Simpson, Levy: Quart. Journ. Med., 1932, xxv, 99

von dem Borne, G. A. K.: Nederl. Tijdschr. v. Geneesk., 1933, lxxvii, 4, p. 433 .

Britton, Harrop, and Weinstein: Journ. Amer. Med. Assoc., 1932 , xcviii, 1525 .

4 Swingle. W. W., and Pfiffner, J. J.: Medicine, 1932, xi, 371.

5 Cecil, H. L: Amer. Journ. Physiol., 1933, c, 463.

- Cecil, H. L.: Amer. Gourn. 1931, xcvii, 1446.

$\checkmark$

\section{TREATMENT AND CONTROL OF ESSENTIAL HYPERTENSION}

\section{A NEW THERAPEUTIC MEASURE}

BY

\section{H. O. GUNEWARDENE, M.B., B.S.LOND.,} D.M.R.E.CANTAB

Late clinical assistant, National hospital for Diseases OF THE HEART, LONDON

In 1917 Cyriax $^{1}$ reported good results in cases of moderately high blood pressure obtained by what he described as " mobilization of the spinal column," by which he meant active and passive movements of the vertebral joints, and passive manipulations, vibrations, pétrissage, etc., of the erector spinae muscles. His explanation of raised pressure was, apparently, that congestion of these parts led to irritative states of the erector spinae, setting up a series of sensory stimuli to the posterior spinal nerves, which in turn gave rise to a series of pressor effects. Whatever the explanation, his figures seemed to show a definite diminution of the blood pressure in his patients.

Although unwilling to accept the theory on which the treatment was based, I ventured to modify his method by substituting electrical stimulation of the skeletal muscles, and submitting patients with high grades of pressure to treatment on these lines. As a preliminary the patients were tested to see what effect the resulting muscular contractions had on the pulse rate, particularly as some of them were on the verge of cardiac failure, a few actually exhibiting oedema of the ankles and a more than moderate enlargement of the heart. In every case the pulse rate dropped, sometimes by eight beats to the minute; in a 
few it remained stationary; in none did it rise. It was argued, therefore, that the method of treatment, instead of throwing a burden on the heart, actually relieved it, and the treatment was carried out with greater zest.

\section{Clinical Material}

Case 1.-A woman, aged 58, and unmarried, complained that her left leg had suddenly become stiff, and that her speech had become bad two years previously. Family history: father had died of "stroke" at the age of 62; he was paralysed for two months; mother had died of bronchitis at the age of 40; one brother had died of nephritis, while two were well; one sister had high blood pressure, one had died of stroke, six were well. Previous history: none of any significance; patient was 'fat two years ago. Habits : no alcohol, no smoking ; exercise, housework.

Condition before treatment: the patient was thin, had left-sided hemiparesis, with dysarthria; she could not get into her car, and walked very slowly. Heart: left border one inch outside mid-clavicular line; first sound + , aortic second sound ++ . Lungs: nil. Blood pressure 240/140. Urine: specific gravity 1014 ; no albumin or sugar. After treatment the blood pressure readings were as follows:

\begin{tabular}{|c|c|c|c|c|c|}
\hline \multicolumn{4}{|c|}{ Date } & \multirow{2}{*}{$\frac{\text { Systolic }}{240}$} & \multirow{2}{*}{$\frac{\text { Diastolic }}{140}$} \\
\hline September & r 12th, 1932 & ... & $\ldots$ & & \\
\hline$n$ & 16th, , & $\ldots$ & $\ldots$ & 200 & 136 \\
\hline$"$ & 21st, , & $\ldots$ & ... & 184 & 130 \\
\hline " & 27th, , & $\ldots$ & ... & 180 & 122 \\
\hline & & & & 230 & 122 \\
\hline$"$ & Sov1, " & $\cdots$ & & 200 & 120 \\
\hline October & Eth, , , & $\ldots$ & $\ldots$ & 175 & 120 \\
\hline
\end{tabular}

The patient states that she can now get into the car alone, " feels lighter," and walks better. The left border of the heart is just outside the mid-clavicular line, with a heaving apex beat and an accentuated aortic second sound.

Case 2.-A woman, aged 56, unmarried, complained of a "swaying feeling in the head" of six months' duration. Family history: as for Case 1. Previous history: none of any significance. Habits: no exercise; no tobacco or alcohol. Heart: left border just outside mid-clavicular line; aortic second sound + . Lungs: nil. Urine: specific gravity 1012 ; no albumin or sugar. Blood pressure readings were as follows:

\begin{tabular}{|c|c|c|c|c|c|}
\hline \multicolumn{4}{|c|}{ Date } & Systolic & Diastolic \\
\hline \multicolumn{2}{|c|}{ September 12th, 1932} & & $\ldots$ & 210 & 128 \\
\hline$"$ & 16th, , & & $\ldots$ & 170 & 110 \\
\hline. & 21st, , & ... & $\ldots$ & 158 & 105 \\
\hline \multirow[b]{2}{*}{$\infty$} & \multirow[b]{2}{*}{ 23rd, " } & \multirow[b]{2}{*}{... } & \multirow{2}{*}{$\ldots 1$} & 160 & \multirow{2}{*}{$\begin{array}{l}105 \\
108\end{array}$} \\
\hline & & & & 178 & \\
\hline ". & 27th, , & $\ldots$ & $\ldots$ & 148 & 98 \\
\hline \multicolumn{6}{|c|}{ (Exercise started) } \\
\hline \multicolumn{2}{|c|}{ September 30th, 1932} & $\ldots$ & $\ldots$ & 170 & 112 \\
\hline \multicolumn{2}{|c|}{ October Eth, $1932 \quad \ldots$} & $\ldots$ & ... & 155 & 106 \\
\hline
\end{tabular}

On October 8th, 1932, the left border of the heart was in the mid-clavicular line; the patient stated that she felt quite well, and had no swaying feeling in the head.

In neither of these cases was rest enjoined or medicine given, and there was no restriction of diet. In both there was marked diminution of the size of the heart, disappearance of symptoms, a considerable fall in the pressure, and obvious general improvement. But one of the patients, the younger, seemed to have improved more than the elder, who appeared, when she first came to me, to have reconciled herself to a condition of inactivity engendered by a fear of fatal apoplexy.

Case 3.-A clerk, aged 49, married, with seven children, when seen on May 18th, 1932, complained of weakness, and, on interrogation, breathlessness and pain over the lower part of the sternum following exertion (of two years' duration). Family history: father died of enlarged liver at the age of 48 ; mother died suddenly of "debility" ; of six brothers, one had kidney disease, two were dead-one dying of typhoid. Previous history: none of any significance. Habits: a little alcohol occasionally., but no tobacco; exercise, a little walking ; food, three good meals a day.

Condition before treatment: Tightness under the sternum, palpitation, dyspnoea on exertion, slight giddiness; bad teeth ; bowels constipated. Pulse 90, regular, and of high tension. Heart: apex beat in the sixth space, anterio axillary line. Vessels: palpable. Blood pressure 260/160 Urine: no albumin. Lungs: nil.

On May 25th the blood pressure had fallen to $218 / 142$, and the patient said he felt better. The following were the blood pressure readings:

\begin{tabular}{|c|c|c|c|}
\hline \multirow{2}{*}{ Date } & \multicolumn{2}{|c|}{ Blood Pressure } & \multirow{2}{*}{ Remarks } \\
\hline & Systolic & Diastolic & \\
\hline May 18th, 1932 & 260 & 160 & - \\
\hline May 25th, ., & 218 & 142 & - \\
\hline May 28th, , & 210 & 120 & $\begin{array}{l}\text { No pain under the sternum; heart } \\
\text { smaller }\end{array}$ \\
\hline June lst. & 192 & 120 & Swaster - \\
\hline June 3rd, , & 190 & 122 & Left border of heart finger- \\
\hline June 6th, , , & - & - & $\begin{array}{l}\text { Left border of heart just outside } \\
\text { nipple line }\end{array}$ \\
\hline June 17th, , & - & - & Left border of heart in nipple line \\
\hline June 22nd, , & 182 & 118 & - \\
\hline Aug. 16th, , & 180 & 115 & $\begin{array}{l}\text { Left border of heart in nipple } \\
\text { line: no pain under sternum }\end{array}$ \\
\hline Aug. 19ith, & - & - & Patient ceased attendance \\
\hline
\end{tabular}

Case 4.-A carpenter, aged 60 , married, with nine children was admitted to hospital on June 17th, 1932; complaining of loss of power of the right limb; he had had a similar attack three years before. Family history: father died, aged 60 (? boil in cherk) ;. mother died, aged 83, of old age. Previous history: malaria, nothing else of significance. Habits: a little alcohol occasionally, but no tobacco; exercise, his work; food, formerly two good meals a day.

Condition before treatment: Slight paresis of left side of face, speech slurring. Pulse 90 ; rhythm regular, high tension. Vessels: thick. Heart: left border half an inch outside the nipple line ; aortic second sound accentuated. Blood pressure 210/110. Urine: a trace of albumin, no casts. Lungs: nil. Wassermann reaction negative. Nervous system: knee-jerks and biceps response normal on the left side.

July 4th, 1932: Babinski's reflex positive on right side ; no sensory phenomena. After daily treatment blood pressure is $132 / 92$. The patient's speech is normal, and power of the lower limbs has returned; the left border of the heart is internal to the nipple line.

Case 5.- Hotel manager, aged 56, married, with ten children, was admitted on April 3rd, 1932. He complained of breathlessness and palpitation, and occasional swelling of the legs. Family history: father died of old age at 72 ; mother died of heart trouble at 68 ; five brothers, all well ; four sisters-one dead, the remainder well. Previous history: was in the police force, 1895-1918; admitted to hospital four times, once with diabetes; had had malaria in 1892. Habits: a fair quantity of alcohol, but no tobacco ; no exercise now.

Condition before treatment: Fat and short-necked type; had palpitation and shortness of breath, while teeth were slightly infected; legs were swollen. Pulse 40, regular. Heart: three-quarters of an inch outside the nipple line, aortic second sound accentuated. Blood pressure 180/120. Lungs: nil. Urine: a trace of albumin, but no casts.

On July 29th the blood pressure was still $180 / 120$, but there was no swelling of the legs; the heart was as before pulse 84 ; no oedema. Patient complained of headache about 1.30 a.m. Renal involvement was feared, and a urea concentration test was done on August 2n (blood urea $27 \mathrm{mg}$. per $100 \mathrm{c.cm}$.). Concentration before test 1.3 per cent.; after one hour 2.5 per cent. ; after two hours 2.0 per cent. ; after 
three hours 2.0 per cent. The treatment was continued, and the following were the subsequent blood pressure readings:

\begin{tabular}{c|c|c|c}
\hline Date & Systolic & Diastolic & Remarks \\
\hline August 8th ... & 162 & 100 & $\begin{array}{l}\text { Patient felt much better; no head- } \\
\text { ache; no swelling of the feet } \\
\text { Left border of heart in the nipple } \\
\text { line. Patient felt much better } \\
\text { Left border of heart in the nipple } \\
\text { line }\end{array}$ \\
\hline August 13th ... & 170 & 106 & - \\
\hline
\end{tabular}

In this case the failure to respond to treatment in the early stages suggested renal involvement and impaired renal function, but the blood urea and the urea concentration test gave figures which indicated efficient functioning. Therefore the treatment was continued until the diastolic pressure fell to 100 , and the patient felt very much better.

Case 6.-Hotel manager, aged 41, married, with two children. He complained of occasional throbbing in the head. Family history: father died at the age of 54 years, and mother at the age of 66 ; two brothers and five sisters, all well. Previous history: patient consulted a doctor about four years previously for " feeling dizzy suddenly," and one year previously had complained of headache ; no history of any other illnesses. Habits : alcohol formerly, but little now ; exercise, only walking associated with work ; tobacco, fifteen cigarettes a day; food, had eaten well previously.

Condition before treatment: Headache occasionally, dyspnoea slight; nothing else of significance. Pulse: 85 regular, good volume and tone. Heart: left border in nipple line, second aortic sound accentuated. Urine: specific gravity 1011, a trace of albumin. Blood pressure $220 / 150$.

Three weeks of treatment made no reduction in his blood pressure. Renal involvement was suspected, and the urea concentration test was done; the concentration in the second hour specimen was 1.7 per cent. Treatment was discontinued, but the patient " felt very much better."

The patients whose records are given above received no special medicine, nor was absolute rest ordered for any of them. Cases 4 and 5 happened to be in hospital; the others came for treatment from home. The diet was restricted in all of them.

\section{Discussion}

Prior to adopting this method of treatment I had tried diathermy in a large number of cases of hypertension. I was never able to convince myself that pressure was reduced to an extent which could not be explained by the simultaneously ordered rest, in spite of Clifford Allbutt's ${ }^{2}$ statement nine years ago that “ d'arsonvalization by the auto-condensation method is the most valuable immediate aid we possess for hyperpiesia." But it was always strikingly evident that this treatment made the patients feel better, particularly when the kidneys appeared to be involved. They nearly always stated they were much better. With the diathermy I often combined radiant heat, particularly in renal cases. The striking reduction of pressure obtained in non-renal cases in the above series would therefore appear to be due to the mobilization of the muscles in the manner described.

The results recorded above indicate:

1. That in some cases of hyperpiesia the blood pressure drops to low limits, even to normal figures, without rest or medicinal aid; there is also relief from distressing symptoms.

2. That in other cases the patients are relieved of their symptoms and proclaim that they feel better, but that pressures will not fall. These cases show impaired renal function as gauged by the urea concentration test.

3 . That the heart enlarged as a result of the strain of hypertension gets astonishingly smaller with the fall of pressure.

It is difficult to give an explanation of the mechanism by which the reduction of pressure is brought about. I was encouraged to try it by my belief that sedentary occupations or lack of sufficient exercise play an important part in the aetiology of essential hypertension, and, if I may be allowed to put it figuratively, that the rusty arterioles and capillaries of sluggish muscles were a cause of elevated pressure. It was found in the series that when an appreciable degree of diminution of pressure was not obtained the urea concentration test showed impaired renal efficiency.
All the patients were treated in hospital. The machine used was the ordinary pantostat-the faradic currentwith a Lewis Jones interrupter in circuit to prevent irregular contractions and uneven, unpleasant shocks. Ordinary batteries have not so far been used, but there is no reason why any method of stimulation should not answer, so long as sudden shocks and irregular contractions are avoided. The Smart-Bristowe coil ought to prove useful. In the absence of electricity, massage would, I imagine, answer ; but I am not in a position to vouch for good results. When pressures drop low as a result of treatment-namely, below a diastolic pressure of 110 - the patients are taught exercises with which the muscles may be kept in action-particularly the trunk muscles-or advice is given that mild exercises may be resorted to. The patient should be carefully watched, particularly when cardiac enlargement and symptoms are present, or the doctor may one day be called upon to face a charge of " electrocution" when death due to heart failure is attributed to electrical shock. I have deliberately refrained from using subsidiary measures in order to establish the efficacy of this method of treatment, but $\mathrm{I}$ am of the belief that therapeutic doses of the drugs ordinarily used (not patent medicines) would prove very useful in maintaining the good results obtained, particularly in those cases in which the blood pressures have not fallen too near normal limits. To establish that the combined measures will give more satisfactory results than those already obtained must remain part of the programme of the future.

So widely is it accepted that arterial hypertension, when it throws its strain on the myocardium, takes the patient gradually to hypertrophy, dilatation, and failure, that we find East and Bain in Recent Advances in Cardiology describing "the third stage" of high blood pressure, as much as to imply that the changes are irrevocable. They probably are, but only when the vessel changes have taken place. If such changes have not taken place it would appear from these observations that extreme grades of enlargement can be reduced to moderate grades, and moderate grades to slight ones.

It is now sixteen years since Cyriax published his paper, but the methods of treatment which might have been developed from his findings are still not in vogue. This method of treatment was referred to briefly by me at the discussion on essential hypertension at the Annual Meeting of the British Medical Association in Dublin.

I have to acknowledge here my gratefulness to Miss Bevan, sister-in-charge of the electrotherapeutic department, General Hospital, Colombo, for the pains she has taken in connexion with these cases, and my indebtedness to my colleagues of that institution for helping me to carry out this treatment on their patients.

${ }^{1}$ Cyriax, E. F. Practitioner, 1917, xcix, 468

2 Allbutt, Sir Clifford: Arteriosclerosis, 1925, p. 91.

\section{Memoranda MEDICAL, SURGICAL, OBSTETRICAL \\ PRIMARY BRONCHIAL CARCINOMA WITH SECONDARY VERTEBRAL DEPOSITS}

This case is of interest because symptoms were due to spinal cord compression, and the nature of the primary growth remained unsuspected till necropsy was performed.

A labourer, aged 50, on May 10th, 1933, noticed pains in both shoulders and in his back, which came on suddenly and forced him to leave his work; he said he was not subject to backache or rheumatism: During the next few days the pains were less troublesome, but on May 13th he became constipated, and medicine afforded him little relief. At the same time he noticed that his urine was cloudy. On May 30 th he complained of weakness and numbness of his lower limbs, the right leg becoming slightly weaker than the left. The next day he was unable to pass water, and was admitted to the medical ward of this hospital.

On examination he was found to be a well-developed man, of good colour, with no signs of muscular wasting. No 